\title{
Does eosinophilic COPD exacerbation have a better patient outcome than non-eosinophilic in the intensive care unit?
}

This article was published in the following Dove Press journal:

International Journal of COPD

8 September 2015

Number of times this article has been viewed

\section{Cüneyt Saltürk \\ Zuhal Karakurt \\ Nalan Adiguzel \\ Feyza Kargin \\ Rabia Sari \\ M Emin Celik \\ Huriye Berk Takir \\ Eylem Tuncay \\ Ozlem Sogukpinar \\ Nezihe Ciftaslan \\ Ozlem Mocin \\ Gokay Gungor \\ Selahattin Oztas}

Respiratory Intensive Care Unit, Sureyyapasa Chest Diseases and Thoracic Surgery Teaching Hospital, İstanbul, Turkey
Correspondence: Cüneyt Saltürk Respiratory Intensive Care Unit,

Sureyyapasa Chest Diseases and Thoracic Surgery Teaching Hospital, Merdivenkoy

District, Ortabahar Street, Hakan

Apartment No 15d, 16 Kadikoy, Istanbul

34732, Turkey

Tel +905326466590

Email csalturk@yahoo.com
Background: COPD exacerbations requiring intensive care unit (ICU) admission have a major impact on morbidity and mortality. Only $10 \%-25 \%$ of COPD exacerbations are eosinophilic.

Aim: To assess whether eosinophilic COPD exacerbations have better outcomes than noneosinophilic COPD exacerbations in the ICU.

Methods: This retrospective observational cohort study was conducted in a thoracic, surgerylevel III respiratory ICU of a tertiary teaching hospital for chest diseases from 2013 to 2014 Subjects previously diagnosed with COPD and who were admitted to the ICU with acute respiratory failure were included. Data were collected electronically from the hospital database. Subjects' characteristics, complete blood count parameters, neutrophil to lymphocyte ratio (NLR), delta NLR (admission minus discharge), C-reactive protein (CRP) on admission to and discharge from ICU, length of ICU stay, and mortality were recorded. COPD subjects were grouped according to eosinophil levels ( $>2 \%$ or $\leq 2 \%$ ) (group 1, eosinophilic; group 2 , non-eosinophilic). These groups were compared with the recorded data.

Results: Over the study period, 647 eligible COPD subjects were enrolled (62 [40.3\% female] in group 1 and 585 [33.5\% female] in group 2). Group 2 had significantly higher C-reactive protein, neutrophils, NLR, delta NLR, and hemoglobin, but a lower lymphocyte, monocyte, and platelet count than group 1, on admission to and discharge from the ICU. Median (interquartile range) length of ICU stay and mortality in the ICU in groups 1 and 2 were 4 days (2-7 days) vs 6 days ( $3-9$ days) $(P<0.002)$, and $12.9 \%$ vs $24.9 \%(P<0.034)$, respectively.

Conclusion: COPD exacerbations with acute respiratory failure requiring ICU admission had a better outcome with a peripheral eosinophil level $>2 \%$. NLR and peripheral eosinophilia may be helpful indicators for steroid and antibiotic management.

Keywords: chronic obstructive pulmonary disease, exacerbation, respiratory failure, intensive care unit, peripheral eosinophilia

\section{Introduction}

COPD exacerbations have a major impact on morbidity and mortality when intensive care unit (ICU) admission is required. ${ }^{1,2}$ Acute respiratory failure (ARF) due to COPD exacerbation is, as a first choice, primarily managed by noninvasive mechanical ventilation (NIMV), and the initiation of NIMV is determined by the severity of ARF. ${ }^{3-5}$ In addition to the application of NIMV, an optimized medical regime should be initiated for successful management. ${ }^{3}$

The optimal medical treatment for COPD exacerbations in the ICU is still controversial. The majority of COPD exacerbations have an infectious origin. ${ }^{6}$ Some studies have investigated the decision to use steroids or antibiotics based on the COPD exacerbation..$^{7-11}$ Sputum and peripheral eosinophilia (2\%-3\% eosinophils) have been 
found in only $10 \%-45 \%$ of COPD exacerbations. ${ }^{12-16}$ The presence of either sputum or peripheral eosinophilia can help physicians to decide on steroid or antibiotic management. ${ }^{1-16}$ Peripheral eosinophilia is thought to be a result of the inflammatory process of COPD exacerbation. ${ }^{12}$ In addition to the presence of eosinophilia, other inflammatory markers such as neutrophil to lymphocyte ratio (NLR), ${ }^{17}$ platelet (PLT) to mean platelet volume (MPV), ${ }^{18}$ and $\mathrm{PLT} / \mathrm{MPV}$ ratio are not well defined in COPD subjects with ARF requiring ICU admission.

There are limited data on peripheral eosinophilia, NLR, PLT/MPV, and outcomes of COPD exacerbation that lead to $\mathrm{ARF}$ and require ICU admission. We hypothesized that the presence of peripheral eosinophilia may result in a better outcome compared with non-eosinophilic exacerbations.

\section{Methods}

This retrospective observational cohort study was conducted in a thoracic, surgery level III respiratory ICU of a tertiary teaching hospital for chest diseases from 2013 to 2014. The Sureyyapasa Chest Disease and Surgery Research Hospital Local Ethics Committee approved the study and was in accordance with the Declaration of Helsinki. Due to the retrospective nature of the study design, informed consent was not obtained. During the study period, the same intensivist specialist team worked in the ICU, which they staffed 24 hours per day.

\section{Subjects}

Subjects previously diagnosed with COPD (ICD coding as J 44) and admitted to the ICU with ARF were included and grouped according to their peripheral eosinophil count on the day of admission. Subject inclusion is summarized in a flowchart (Figure 1). The COPD diagnosis was established by a physician who evaluated airflow obstruction on spirometry, forced expiratory volume in 1 second $\left(\mathrm{FEV}_{1}\right)$ of $70 \%$ predicted or less, and an $\mathrm{FEV}_{1}$ and forced vital capacity ratio of $70 \%$ or less. ${ }^{3}$ Spirometry test data could not be recorded from the subjects' charts. The smoking history of patients was recorded.

\section{Definitions}

Hypoxic ARF was defined as the ratio of partial arterial oxygen pressure to inspired fractionated oxygen $\left(\mathrm{PaO}_{2} /\right.$ $\left.\mathrm{FiO}_{2}\right)<300$ and partial arterial carbon dioxide pressure $\left(\mathrm{PaCO}_{2}\right)<45 \mathrm{mmHg}$. Hypercapnic/hypoxemic ARF was defined as $\mathrm{PaCO}_{2}>45 \mathrm{mmHg}$ and $\mathrm{PaO}_{2} / \mathrm{FiO}_{2}<300$. Hypercapnic ARF was $\mathrm{PaCO}_{2}>45 \mathrm{mmHg}$ and $\mathrm{PaO}_{2} /$ $\mathrm{FiO}_{2}>300 .^{5,19}$

The COPD exacerbation due to an infectious origin was defined by the presence of all three Anthonisen criteria, as follows: worsening of dyspnea, increased volume of pulmonary secretions (endotracheal, sputum), and increased purulence of respiratory secretions. ${ }^{3,20}$

Peripheral eosinophilia, defined by an eosinophil count higher than $2 \%$, was accepted as eosinophilic COPD

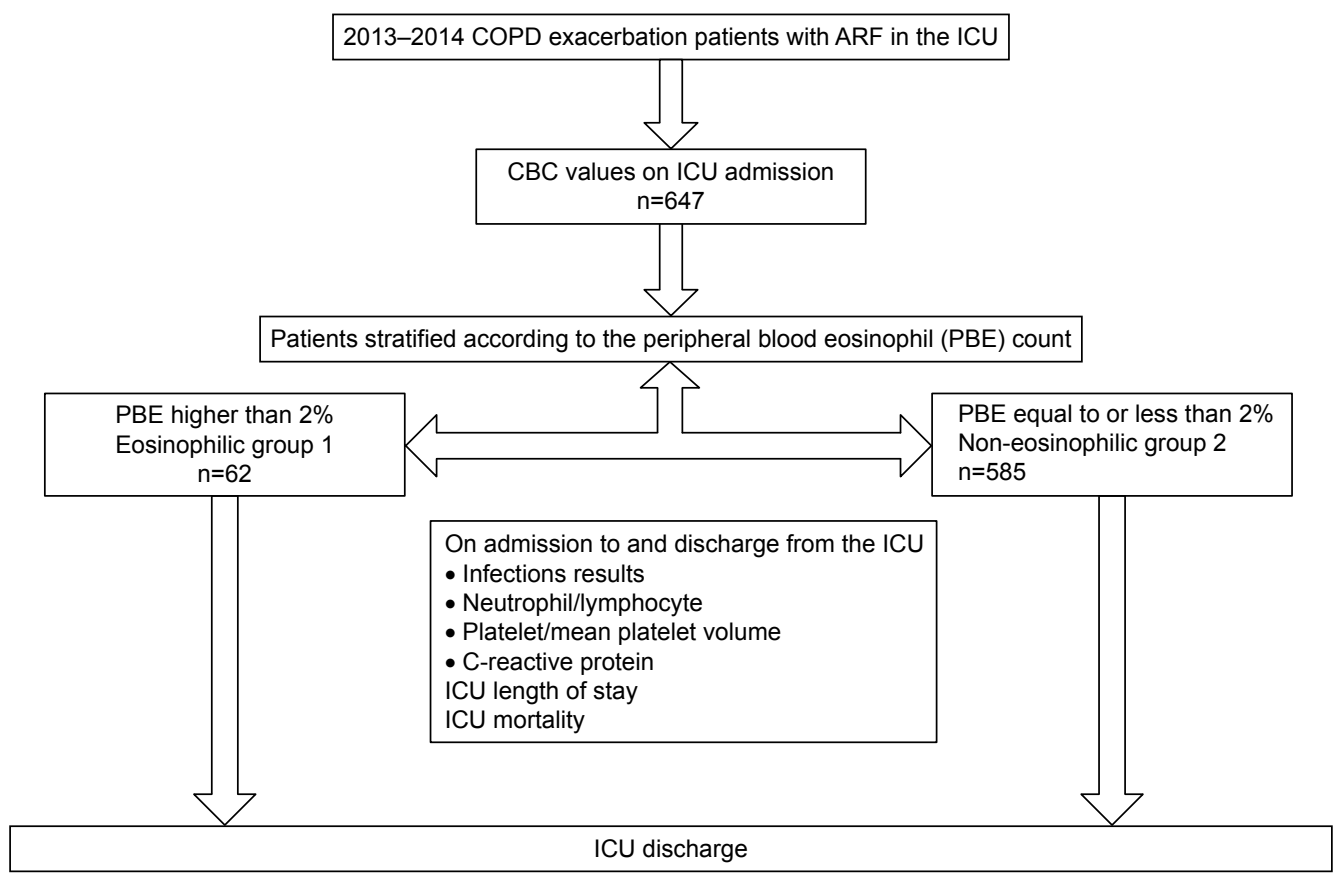

Figure I Flowchart of patient enrollment.

Abbreviations: ARF, acute respiratory failure; $C B C$, complete blood count; ICU, intensive care unit. 
exacerbation, and if the peripheral blood eosinophil count was equal to or less than $2 \%$, it was defined as a non-eosinophilic COPD exacerbation. ${ }^{13}$ The cutoff of $2 \%$ peripheral blood eosinophils has been shown to have a sensitivity of $90 \%$ and specificity of $60 \%$ for identifying a sputum eosinophilia of greater than $3 \%$ at the time of exacerbation. ${ }^{13}$

The NLR was calculated as an indicator of the systemic inflammatory response. PLT to MPV: MPV correlates with PLT activity.

Delta values were used to show the differences between values at ICU admission and at the time of ICU discharge.

\section{Data}

Data were collected electronically from the hospital database. Subject's characteristics, comorbid diseases, APACHE II scores, ${ }^{21}$ complete blood count (CBC) parameters, NLR, delta NLR (admission minus discharge), C-reactive protein (CRP), biochemistry and arterial blood gas (ABG) values on admission to and discharge from the ICU, length of ICU stay (LOS days), and mortality were recorded. COPD subjects were divided into two groups according to their peripheral eosinophil count (group 1, eosinophilic [ $>2 \%$ ]; group 2, noneosinophilic $[\leq 2 \%]$ ) (Figure 1). The groups were compared with the recorded data.

\section{Mechanical ventilation}

Initially, NIMV was applied to all COPD subjects with hypercapnic respiratory failure unless absolutely contraindicated. ${ }^{19}$ Contraindications of NIMV were defined as 1) absolute, respiratory arrest and inability to fit mask and 2) relative, medically unstable (hypotensive shock, uncontrolled cardiac ischemia or arrhythmia, uncontrolled copious upper gastrointestinal bleeding), agitation, uncooperativeness, inability to protect airway, impaired swallowing, excessive secretions not managed by secretion clearance techniques, multiple (two or more) organ failure, and recent upper airway or upper gastrointestinal surgery. ${ }^{5,22} \mathrm{NIMV}$ was provided in pressure assist-control mode with ICU mechanical ventilators via a double-tube circuit with a full-face mask. Pressure support was initially set at $8-10 \mathrm{~cm} \mathrm{H}_{2} \mathrm{O}$ and gradually increased to a maximum of $30 \mathrm{~cm} \mathrm{H}_{2} \mathrm{O}$ until the exhaled tidal volume was 5-7 mL/kg and guided by subject tolerance. Positive endexpiratory pressure was set at $5 \mathrm{~cm} \mathrm{H}_{2} \mathrm{O}$ and raised or lowered to treat hypoxemia or enhance subject comfort, respectively. The reasons for NIMV failure in hypercapnic subjects were no $\mathrm{pH}$ improvement, no change or a rise in breathing frequency after 1-2 hours, and lack of cooperation.

Invasive mechanical ventilation (IMV) was applied in the presence of absolute or relative contraindications for
NIMV, as mentioned earlier. It was applied by assist-control ventilation in pressure control mode. Inspiratory pressure was set for a target tidal volume of 5-7 mL/kg ideal body weight (Airway plateau pressure $<30 \mathrm{~cm} \mathrm{H}_{2} \mathrm{O}$ ) under a sedation protocol. The Richmond agitation sedation scale was used for infusion and assessment of the daily need for sedation. ${ }^{23}$ When subjects met the previously described criteria for weaning, the pressure support ventilation mode was used and gradually decreased (1-2 cm $\mathrm{H}_{2} \mathrm{O}$ every $1-2$ hours), and when the T-piece trial duration was 30 minutes, they were extubated. ${ }^{24}$

\section{Bronchodilator and anti- inflammatory treatment in the ICU}

While the subjects were under NIMV or IMV, a short-acting $\beta 2$ agonist (salbutamol, $100 \mu \mathrm{g}$ per puff) and ipratropium bromide $(100 \mu \mathrm{g} / 20 \mu \mathrm{g}$ per puff) was given every $2-4$ hours (four to ten puffs) via a metered dose inhaler chamber (Aerovent, Altech $^{\circledR}$, Altera Firm, Izmir, Turkey). A nebular form of salbutamol (2.5 mg/2.5 mL per nebule) was given every 15 minutes to 4 hours, or ipratropium bromide/salbutamol ( $0.5 \mathrm{mg} / 3.01 \mathrm{mg} / 2.5 \mathrm{~mL}$ per nebule) was given every $2-4$ hours for subjects breathing without mechanical ventilation support. Long-acting $\beta 2$ agonists were not used in COPD subjects with $\mathrm{ARF}$ in the ICU. Intravenous methylprednisolone (40-60 mg) was given one-two times daily as an anti-inflammatory for those subjects unable to take oral medications, or those (eligible) subjects with impaired gastrointestinal absorption. The steroid dose was tapered gradually and discontinued over 7 to 10 days. Methylxanthines (theophylline and aminophylline) were not given. All subjects received oxygen for COPD, as well as medication to treat the underlying cause of ICU admission or ARF and comorbidities. ${ }^{1,25,26}$

\section{Statistical analysis}

A descriptive analysis was used to investigate subject demographics and ICU data. Groups were compared using the Mann-Whitney $U$-tests for nonparametric continuous variables or the Student's $t$-tests for parametric continuous variables. The chi-square test was employed for dichotomous variables. The median with interquartile range (IQR) was employed for nonparametric continuous variables, and mean \pm standard deviation was used for parametric continuous variables. Count and percentage were used when applicable. Logistic regression analysis was performed to define mortality risk factors in the study population. Age, sex, body mass index, IMV, NIMV applications, peripheral eosinophilia, long-term oxygen or NIMV use, APACHE II score on admission to the ICU, septic shock, resistant pathogen, a CRP greater than 
$50 \mathrm{mg} / \mathrm{dl}$, and an NLR $\geq 16$ were included in the model. A $P$-value $<0.05$ was accepted as statistically significant.

\section{Results}

During the study period, $9.6 \%$ of the enrolled subjects had eosinophilic COPD (group 1, peripheral blood eosinophil count $>2 \%$ ), and the remainder had non-eosinophilic COPD (group 2, peripheral blood eosinophil count $\leq 2 \%$ ). The subject demographics, smoking history, and ICU data are summarized in Table 1. Both groups were aged more than 65 years, and the majority was male with a similar body mass index within the normal range. Where the patient was prior to ICU admission and the length of pre-ICU hospital stay are also summarized in Table 1. Three hundred and eighteen (49.1\%) patients were admitted from the general ward or other ICU, and the median length of stay was 4 days (IQR,

Table I Demographics and ICU values of study groups

\begin{tabular}{|c|c|c|c|}
\hline & Group I $(n=62)$ & Group $2(n=585)$ & $P$-value \\
\hline Age, years, median (IQR) & $67(54-78)$ & $69(60-77)$ & 0.21 \\
\hline Sex, male, $n(\%)$ & $51(82.3)$ & $472(80.7)$ & 0.28 \\
\hline Body mass index, $\mathrm{kg} / \mathrm{m}^{2}$, median (IQR) & $23(19-26)$ & $23(20-29)$ & 0.32 \\
\hline \multicolumn{4}{|l|}{ Smoke exposure, n (\%) } \\
\hline Active cigarette smoker & $26(4 I .9)$ & $206(35.2)$ & 0.50 \\
\hline Ex-cigarette smoker & $15(24.2)$ & $177(30.3)$ & na \\
\hline Smoke other than cigarette & $21(33.4)$ & $202(34.5)$ & na \\
\hline Biomass exposure & $19(30.6)$ & $150(25.6)$ & 0.39 \\
\hline Pack-years, median (IQR) & $40(30-60)$ & $43(30-60)$ & 0.77 \\
\hline \multicolumn{4}{|l|}{ Comorbid diseases, n (\%) } \\
\hline Diabetes mellitus & $15(24)$ & $112(19)$ & 0.35 \\
\hline Hypertension & $20(32)$ & $231(40)$ & 0.26 \\
\hline Congestive heart failure & $20(32)$ & $193(33)$ & 0.89 \\
\hline Arrhythmia & $19(31)$ & $107(18)$ & 0.02 \\
\hline Malignancy & $9(15)$ & $59(10)$ & 0.28 \\
\hline Chronic renal diseases & $2(3)$ & $22(4)$ & 0.83 \\
\hline Long-term oxygen therapy & $35(57)$ & $303(52)$ & 0.52 \\
\hline Long-term home NIMV & $27(44)$ & $175(30)$ & 0.031 \\
\hline \multicolumn{4}{|l|}{ Pre-ICU location, $n(\%)$} \\
\hline Ward & $19(31.7)$ & $253(46.7)$ & 0.001 \\
\hline Emergency department & $25(41.7)$ & $273(46.7)$ & na \\
\hline Outpatient clinic & $9(15.0)$ & $19(3.3)$ & na \\
\hline Other ICU & $7(11.7)$ & $39(6.7)$ & na \\
\hline Pre-ICU ward day, median (IQR) & $5(4-10)$ & $3(I-6)$ & 0.001 \\
\hline \multicolumn{4}{|l|}{ ICU data } \\
\hline APACHE II, median (IQR) & $17(12-24)$ & $20(16-25)$ & 0.002 \\
\hline Sepsis, n (\%) & $18(29)$ & $220(38)$ & 0.17 \\
\hline Septic shock, n (\%) & $6(10)$ & $123(2 \mid)$ & 0.032 \\
\hline Culture performed, n (\%) & $28(45)$ & $302(52)$ & 0.31 \\
\hline Resistant pathogen $\mathrm{n}(\%)$ & I (I.6) & $104(28)$ & 0.001 \\
\hline \multicolumn{4}{|l|}{ Arterial blood gas on admission } \\
\hline $\mathrm{pH}$ & $7.40(7.30-7.44)$ & $7.30(7.24-7.38)$ & 0.001 \\
\hline $\mathrm{PaCO}_{2}, \mathrm{mmHg}$ & $53(36-68)$ & $65(45-8 I)$ & 0.005 \\
\hline $\mathrm{PaO}_{2} / \mathrm{FiO}_{2}$ & $169(114-352)$ & $180(120-258)$ & 0.61 \\
\hline $\mathrm{HCO}_{3}, \mathrm{mmol}$ & $29(25-35)$ & $30(24-36)$ & 0.72 \\
\hline $\mathrm{SatO}_{2} \%$ & $95(89-98)$ & $95(90-98)$ & 0.97 \\
\hline \multicolumn{4}{|l|}{ Mechanical ventilation } \\
\hline NIMV, n (\%) & $33(53)$ & $435(75)$ & 0.001 \\
\hline NIMV days, median (IQR) & $3(2-6)$ & $4(2-7)$ & 0.11 \\
\hline NIMV failure to IMV, n (\%) & $10(16)$ & $189(32)$ & 0.008 \\
\hline IMV, n (\%) & $31(50)$ & $274(47)$ & 0.65 \\
\hline IMV days, n (\%) & $2(I-6)$ & $3(I-7)$ & 0.17 \\
\hline Length of ICU stay, days, median (IQR) & $4(2-7)$ & $6(3-9)$ & 0.002 \\
\hline ICU mortality, n (\%) & $8(12.9)$ & $146(24.9)$ & 0.034 \\
\hline
\end{tabular}

Note: Eosinophilic COPD group I (peripheral blood eosinophil count $>2 \%$ ), non-eosinophilic COPD group 2 (peripheral blood eosinophil count $\leq 2 \%$ ).

Abbreviations: ICU, intensive care unit; NIMV, noninvasive mechanical ventilation; IMV, invasive mechanical ventilation; IQR, interquartile range: $25 \%-75 \%$; na, not applicable. 
1-7 days). Half of cases in both groups had received longterm oxygen therapy and one-third of the subjects in group 2 had home NIMV. Comorbidities were similar in both groups, except arrhythmia. The non-eosinophilic COPD subjects were significantly more severe (greater APACHE II score), more acidotic and hypercapnic (Table 1). Half of the subjects in both groups had cultures analyzed and the non-eosinophilic group had a significantly higher rate of resistant pathogen and septic shock (Table 1). The study groups were further subgrouped according to the presence of arrhythmia and the use of home ventilation. There were no significant differences in the recorded data among these subgroups. However, $\mathrm{PaO}_{2} /$ $\mathrm{FiO}_{2}$ ratios of patients with arrhythmia were slightly more hypoxemic in both the eosinophilic and non-eosinophilic groups $\left(\mathrm{PaO}_{2} / \mathrm{FiO}_{2}\right.$ ratio: 130 vs 152 , respectively).

The mechanical ventilation approach and ICU mortality are summarized for the eosinophilic and non-eosinophilic COPD subjects groups in Figure 2. The eosinophilic group required a higher rate of initial IMV (33.9\%), and these patients had a significantly higher rate of arrhythmia $(P<0.02)$ and deeper hypoxemia (Table 1$)$. The mortality of those patients was $14.3 \%$. Although the non-eosinophilic COPD patients needed $14.5 \%$ of initial IMV, the mortality rate was much higher at $45.8 \%$. NIMV failure rate (death and intubation) was higher in the non-eosinophilic group than the eosinophilic COPD patients (50.6\% vs 39.4\%) (Figure 2). In the present study, the non-eosinophilic group had a significantly longer ICU stay and a higher mortality.
$\mathrm{CBC}$ values on admission to and discharge from the ICU for both groups are shown in Table 2. CBC values on admission and discharge for each patient group are compared separately in Table 3. Nearly all parameters of CBC values, except mean corpuscular volume (MCV), were significantly different in both groups. The non-eosinophilic group had significantly higher neutrophils, erythrocytes, and MPV, and a lower lymphocyte and PLT count at both admission and discharge.

Table 4 shows the inflammatory biomarkers of both groups on ICU admission and on ICU discharge. CRP values (on admission to and discharge from ICU) were similar in both groups. However, delta NLR was significantly lower in the eosinophilic COPD group compared with the non-eosinophilic group. PLT to MPV was higher in the eosinophilic group, both on admission to and discharge from the ICU. Delta PLT to MPV was similar in both groups (Table 4). Steroid and antibiotic use are summarized in Table 4.

A logistic regression analysis was performed to identify mortality risk factors. We included age, sex, body mass index, IMV, NIMV applications, peripheral eosinophilia, long-term oxygen or NIMV use, APACHE II score on admission to the ICU, presence of arrhythmia, septic shock, resistant pathogen, a CRP greater than $50 \mathrm{mg} / \mathrm{mL}$, and an NLR $\geq 16$. The presence of septic shock, arrhythmia, age more than 80 years, resistant pathogen infection, the need for IMV, an NLR $\geq 16$, and a CRP greater than $50 \mathrm{mg} / \mathrm{mL}$ were all found to be risk factors for mortality. The prior use of home NIMV was found to significantly reduce the risk of mortality in the ICU (Table 5).

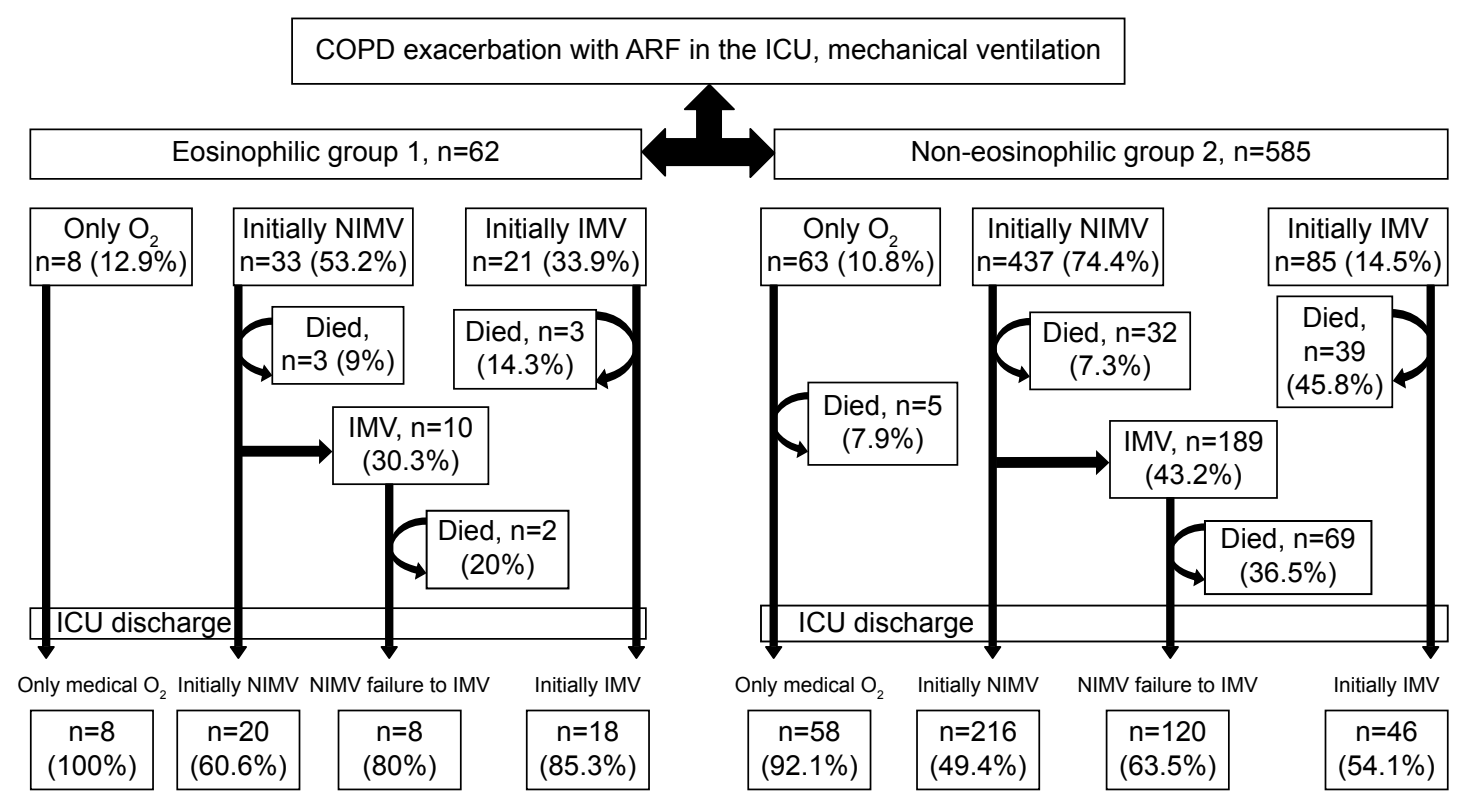

Figure 2 Respiratory treatment approach and outcome for study groups.

Abbreviations: ARF, acute respiratory failure; ICU, intensive care unit; IMV, invasive mechanical ventilation; NIMV, noninvasive mechanical ventilation. 
Table 2 Complete blood count values of study groups on admission to and discharge from the ICU

\begin{tabular}{|c|c|c|c|c|c|c|}
\hline & \multicolumn{3}{|l|}{ Admission } & \multicolumn{3}{|l|}{ Discharge } \\
\hline & Group I $(n=62)$ & Group $2(n=585)$ & $P$-value & Group I $(n=62)$ & Group $2(n=585)$ & $P$-value \\
\hline Leucocyte count, $10^{9} \mathrm{~L}$ & $8.9(7.0-12.5)$ & $11.1(8.2-15.4)$ & 0.001 & $8.7(7.2-10.8)$ & $9.7(7.1-12.9)$ & 0.11 \\
\hline Neutrophil, \% & $72(67-79)$ & $87(80-92)$ & 0.001 & $70(62-76)$ & $79(70-86)$ & 0.001 \\
\hline Monocyte, \% & $6.7(4.8-8.7)$ & $4.8(2.7-7.5)$ & 0.001 & $6.5(5.0-8.5)$ & $6.7(4.5-9.3)$ & 0.64 \\
\hline Lymphocyte, \% & $15.8(\mid 1.9-20.5)$ & $6.7(3.9-11.0)$ & 0.001 & $18.7(\mid 2.1-23.5)$ & II.6 (6.8-17.9) & 0.001 \\
\hline Eosinophil, \% & $2.87(2.30-4.20)$ & $0.20(0.03-0.80)$ & 0.001 & $3.87(2.10-7.00)$ & $0.90(0.17-2.10)$ & $0.00 \mathrm{I}$ \\
\hline Basophil, \% & $0.40(0.20-0.68)$ & $0.15(0.07-0.40)$ & 0.001 & $0.31(0.10-0.60)$ & $0.20(0.10-0.50)$ & 0.09 \\
\hline Erytrocyte count, $10^{12} \mathrm{~L}$ & $3.9(3.5-4.2)$ & $4.32(3.82-4.87)$ & 0.001 & $3.8(3.4-4.2)$ & $4.05(3.5 \mathrm{I}-4.65)$ & 0.003 \\
\hline Hemoglobin, g/dL & $10.7(9.7-12.3)$ & $12.1(10.7-13.5)$ & 0.001 & $10.4(9.3-12.0)$ & $11.4(10.0-12.0)$ & 0.012 \\
\hline Hematocrit, \% & $34.3(29.7-37.6)$ & $37.4(33.2-42.3)$ & 0.001 & $32.3(29.0-35.9)$ & $35.2(30.6-39.7)$ & 0.003 \\
\hline $\mathrm{MCV}, \mathrm{fL}$ & $87(82-92)$ & $87(82-91)$ & 0.99 & $88(83-92)$ & $87(82-91)$ & 0.64 \\
\hline Platelet count, $10^{9} \mathrm{~L}$ & $267(213-377)$ & $236(183-308)$ & 0.004 & $261(197-337)$ & $219(165-284)$ & 0.001 \\
\hline$M P V, f L$ & $8.5(7.6-9.1)$ & $8.8(8.2-9.6)$ & 0.003 & $8.8(8.1-9.4)$ & 9.1 (8.3-9.9) & 0.013 \\
\hline
\end{tabular}

Note: Eosinophilic COPD group I (peripheral blood eosinophil count $>2 \%$ ), non-eosinophilic COPD group 2 (peripheral blood eosinophil count $\leq 2 \%$ ). Data is presented as median (IQR).

Abbreviations: ICU, intensive care unit; MCV, mean corpuscular volume; MPV, mean platelet volume.

Table 3 Comparison of complete blood count values on admission and discharge for each group

\begin{tabular}{|c|c|c|c|c|c|c|}
\hline & \multicolumn{3}{|l|}{ Group I $(n=62)$} & \multicolumn{3}{|c|}{ Group $2(n=585)$} \\
\hline & Admission & Discharge & $P$-value & Admission & Discharge & $P$-value \\
\hline Leucocyte count, $10^{9} \mathrm{~L}$ & $8.9(7.0-12.5)$ & $8.7(7.2-10.8)$ & 0.16 & II.I (8.2-15.4) & $9.7(7.1-12.9)$ & 0.001 \\
\hline Neutrophil, \% & 72 (67-79) & $70(62-76)$ & 0.83 & $87(80-92)$ & $79(70-86)$ & 0.001 \\
\hline Monocyte, \% & $6.7(4.8-8.7)$ & $6.5(5.0-8.5)$ & 0.61 & $4.8(2.7-7.5)$ & $6.7(4.5-9.3)$ & 0.001 \\
\hline Lymphocyte, \% & $15.8(11.9-20.5)$ & I8.7 (I2. I-23.5) & 0.54 & $6.7(3.9-11.0)$ & $11.6(6.8-17.9)$ & 0.001 \\
\hline Eosinophil, \% & $2.87(2.30-4.20)$ & $3.87(2.10-7.00)$ & 0.64 & $0.20(0.03-0.80)$ & $0.90(0.17-2.10)$ & 0.001 \\
\hline Basophil, \% & $0.40(0.20-0.68)$ & $0.31(0.10-0.60)$ & 0.027 & $0.15(0.07-0.40)$ & $0.20(0.10-0.50)$ & 0.001 \\
\hline Erythrocyte count, $10^{12} \mathrm{~L}$ & $3.9(3.5-4.2)$ & $3.8(3.4-4.2)$ & 0.002 & $4.32(3.82-4.87)$ & $4.05(3.51-4.65)$ & 0.001 \\
\hline Hemoglobin, g/dL & $10.7(9.7-12.3)$ & $10.4(9.3-12.0)$ & 0.002 & I2.I (10.7-|3.5) & II.4 (10.0-12.0) & 0.001 \\
\hline Hematocrit, \% & $34.3(29.7-37.6)$ & $32.3(29.0-35.9)$ & 0.001 & $37.4(33.2-42.3)$ & $35.2(30.6-39.7)$ & 0.001 \\
\hline $\mathrm{MCV}, \mathrm{fL}$ & $87(82-92)$ & $88(83-92)$ & 0.86 & $87(82-91)$ & $87(82-91)$ & 0.21 \\
\hline Platelet count, $10^{9} \mathrm{~L}$ & $267(2 \mid 3-377)$ & $26 \mid(197-337)$ & 0.56 & $236(183-308)$ & $219(165-284)$ & 0.001 \\
\hline Mean platelet volume & $8.5(7.6-9.1)$ & $8.8(8.1-9.4)$ & 0.001 & $8.8(8.2-9.6)$ & 9.1 (8.3-9.9) & 0.001 \\
\hline
\end{tabular}

Note: Eosinophilic COPD group I (peripheral blood eosinophil count $>2 \%$ ), non-eosinophilic COPD group 2 (peripheral blood eosinophil count $\leq 2 \%$ ). Data is presented as median (IQR).

Abbreviations: MCV, mean corpuscular volume; ICU, intensive care unit.

Table 4 On the day of admission to and discharge from the ICU for CRP, neutrophil to lymphocyte ratio and platelet to MPV ratio and delta values of study groups

\begin{tabular}{|c|c|c|c|}
\hline & Group I & Group 2 & $P$-value \\
\hline $\mathrm{CRP}, \mathrm{mg} / \mathrm{dL}$ on admission to the ICU & $39.3(14.1-100.0)$ & $52.7(16.7-128.0)$ & 0.24 \\
\hline CRP, mg/dL discharge from ICU & $41.5(18.0-89.0)$ & $43.0(17.0-98.0)$ & 0.59 \\
\hline CRP, $\mathrm{mg} / \mathrm{dL}$ maximum value in the ICU & $65.5(24.0-155.0)$ & $105.0(35.8-184.0)$ & 0.06 \\
\hline Neutrophil to lymphocyte ratio on admission to the ICU & $4.6(3.2-6.8)$ & $13.0(7.3-23.1)$ & 0.001 \\
\hline Neutrophil to lymphocyte ratio discharge from ICU & $3.7(2.7-6.6)$ & $6.8(4.0-12.6)$ & 0.001 \\
\hline Platelet to MPV ratio on admission to the ICU & $30.7(22.6-47.3)$ & $26.3(19.6-40.0)$ & 0.002 \\
\hline Platelet to MPV ratio discharge from ICU & $30.6(21.7-45.0)$ & $24.0(17.2-33.0)$ & 0.001 \\
\hline Delta neutrophil to lymphocyte ratio & $0.29(-1.0-2.1)$ & $4.4(0.0-12.6)$ & 0.001 \\
\hline Delta platelet to MPV ratio & $1.32(-2.2-6.0)$ & I.8 $(-1.8-7.9)$ & 0.42 \\
\hline Delta CRP, mg/dL & $0.0(0.0-12.4)$ & $0.0(0.0-53.7)$ & 0.049 \\
\hline Antibiotic usage, n (\%) & $5 \mathrm{I}(82.3 \%)$ & $540(92.5 \%)$ & 0.006 \\
\hline Steroid usage, n (\%) & $4(6.5 \%)$ & $168(28.9 \%)$ & 0.0001 \\
\hline
\end{tabular}

Notes: Eosinophilic COPD group I (peripheral blood eosinophil count $>2 \%$ ), non-eosinophilic COPD group 2 (peripheral blood eosinophil count $\leq 2 \%$ ). Delta: values on ICU admission minus values on ICU discharge. Data is presented as median (IQR).

Abbreviations: CRP, C-reactive protein; ICU, intensive care unit; MPV, mean platelet volume. 
Table 5 Logistic regression analysis of intensive care mortality risk factors of COPD patients with acute respiratory failure

\begin{tabular}{lllll}
\hline & Odds ratio & \multicolumn{2}{c}{$\mathbf{9 5 \% \text { confidence interval }}$} & P-value \\
\cline { 3 - 4 } & & Lower & Upper \\
\hline Presence of septic shock & 4.20 & 2.21 & 7.99 & 0.001 \\
Presence of arrhythmia & 2.50 & 1.34 & 4.67 & 0.004 \\
Being age 80 years and above & 2.37 & 1.29 & 4.63 & 3.99 \\
Presence of infection with resistant pathogen & 2.12 & 1.12 & 4.04 & 0.012 \\
IMV application & 2.10 & 1.09 & 3.39 & 0.020 \\
NLR equal and above 16 & 1.96 & 1.13 & 3.14 & 0.016 \\
CRP 50 mg/dL and above & 1.78 & 1.01 & 0.04 & 0.047 \\
Home NIMV use & 0.33 & 0.17 & 0.001 \\
\hline
\end{tabular}

Abbreviations: CRP, C-reactive protein; IMV, invasive mechanical ventilation; NIMV, noninvasive mechanical ventilation; NLR, neutrophil to lymphocyte ratio.

\section{Discussion}

We found that only $10 \%$ of COPD patients with ARF had peripheral blood eosinophilia. The non-eosinophilic COPD exacerbation group had a higher APACHE II score and worse arterial blood gas on admission. The non-eosinophilic group used NIMV more often initially and had a higher NIMV failure rate, a longer ICU stay, a significantly higher rate of septic shock and resistant pathogen infection, and an increased ICU mortality despite similar steroid and antibiotic usage. Patients with eosinophilic COPD exacerbation had a lower rate of NLR than those with non-eosinophilic COPD exacerbations in the ICU. In contrast to the non-eosinophilic group, the eosinophilic group showed no significant change in NLR during the treatment period. Patients with eosinophilic exacerbations had a higher rate of PLT to MPV compared with the non-eosinophilic group, both on admission to, and discharge from the ICU.

\section{COPD exacerbation requiring ICU admission and peripheral blood biomarkers: CRP, NLR, and PLT to MPV}

Studies have shown that the primary etiology of COPD exacerbations is due to infection, either viral or bacterial, or both, and these are associated with high economic costs and an accelerated lung function decline. ${ }^{3,25}$ The type of inflammation in subjects with COPD exacerbations is neutrophilic, but eosinophilic inflammation is also observed in $10 \%$ to $45 \%$ of COPD exacerbations. ${ }^{11-16}$ Bafadhel et al showed that the peripheral eosinophil count is a valid biomarker of COPD exacerbation and they also showed that the $2 \%$ threshold value is a sensitive marker for the presence of an eosinophilic attack of COPD that can be corticosteroid responsive. ${ }^{13-16}$ The prevalence of eosinophilic inflammation in COPD subjects was assessed by Singh et al and samples from the Evaluation of COPD Longitudinally to Identify Predictive Surrogate Endpoints cohort were included; they found that $37 \%$ of the COPD subjects had blood eosinophil counts persistently $\geq 2 \%{ }^{27}$ In the present study, only $10 \%$ of the subjects with a COPD exacerbation requiring ICU admission had a peripheral blood eosinophil count greater than $2 \%$. The prevalence of eosinophilic inflammation in COPD subjects requiring ICU is, thus far, not well defined.

CRP is the most well-known inflammatory biomarker. A diagnosis of COPD exacerbation can be more sensitive if the COPD patient has a CRP $>8 \mathrm{mg} / \mathrm{mL}$ together with increasing dyspnea, sputum, volume, or purulence. ${ }^{28}$ However, this study pointed out that CRP alone is not sufficient and not sensitive and specific enough to confirm an exacerbation. Raised CRP levels also do not reflect the clinical severity of the attack. ${ }^{28}$ Daniels et al showed that if CRP values are greater than $50 \mathrm{mg} / \mathrm{mL}$, the subjects had a better response to antibiotic treatment. ${ }^{7}$ Although the present study was not designed to compare the effect of CRP levels, the majority of patients had CRP levels greater than $50 \mathrm{mg} / \mathrm{mL}$. Almost all the patients were treated with antibiotics, either pre-ICU or in the ICU. The decision to use antibiotics was based on a standard general clinical practice approach, without controlled NLR or peripheral eosinophilia. However, if the decision to treat with antibiotics was made according to novel infectious and inflammatory markers such as NLR, MPV, and PLT/MPV, would the outcome of patients with COPD have been better? This may be the subject for future well-designed studies.

Despite steroid and antibiotic treatment, and mechanical ventilation (NIMV or IMV), COPD exacerbations still present a major issue and contribute significantly toward morbidity and mortality in this cohort. In the present study, all eosinophilic and non-eosinophilic COPD patients used steroids and antibiotics, either pre-ICU hospital stay, or in the ICU showed an overall mortality of $25 \%$. The study design did not include an analysis of steroid use and inflammatory response, and as such, the detailed history of steroid usage 
(at home, and in the emergency department and ward), doses, and duration were not recorded. There are several novel monoclonal antibodies and small molecule antagonists that have been evaluated in clinical trials for the management of COPD exacerbation with promising results. These agents can be particularly successful with appropriate COPD subtype selection. ${ }^{29}$ Recently, Brightling et al published a randomized placebo-controlled phase IIa study that evaluated benralizumab, an interleukin-5 receptor alpha monoclonal antibody, which depletes blood and sputum eosinophils in patients with COPD exacerbation. ${ }^{30}$ They assessed the ability of benralizumab to reduce the annualized rate of acute exacerbations of COPD. Although they were unable to show a decline of the COPD annualized rate of acute exacerbations, their subgroup analysis did show that patients with baseline blood eosinophil concentrations of 200 cells per $\mu \mathrm{L}$ had a greater improvement of acute exacerbation of COPD and $\mathrm{FEV}_{1}$ (statistically nonsignificant).

Identifying biomarkers of COPD exacerbations could be helpful in defining the concept of different "exacerbation phenotypes". The more common exacerbation is bacterial (non-eosinophilic). Recently, Günay et al studied the NLR and MPV in COPD subjects during the stable period and during acute exacerbation and they found that COPD subjects had higher NLR and CRP and lower MPV than healthy subjects (MPV and NLR: healthy subjects, 10.1 and 1.71; stable COPD subjects, 8.80 and 2.59; and exacerbation of COPD, 8.0 and 4.28, respectively). ${ }^{17}$ Our study showed similar results for MPV; however, NLR was nearly three times higher in the non-eosinophilic COPD exacerbation subjects than in the COPD exacerbation subjects in Günay et al's study. ${ }^{17}$ NLR values are increased according to the severity of COPD attack. Thus, NLR may be helpful when deciding on a treatment management plan according to the type of COPD exacerbation. In the present study, the NLR was nearly three times higher in the non-eosinophilic group than the eosinophilic group, and this may help to indicate the severity of infectious and inflammatory COPD exacerbation.

\section{ICU outcomes, length of stay, and mortality}

A previously published study investigating the outcomes of ARF subjects with COPD requiring ICU admission from 2008 to $2012(n=1,013)$ showed a $16.9 \%$ mortality rate. ${ }^{31}$ Mortality in 698 subjects with COPD exacerbations of infectious origin was $21.6 \%$; however, COPD subjects with pneumonia $(n=241)$ had a higher rate of mortality $(39 \%)$. Factors indicating a poor prognosis for COPD subjects in the ICU are the need for IMV, presence of pneumonia, cachexia, coronary artery diseases, arrhythmia, hypertension, and higher APACHE II scores. ${ }^{31}$ Mortality risk factors in the present study were found to be similar: the need for IMV, the presence of arrhythmia as a comorbidity, the presence of septic shock and a resistant pathogen infection, CRP values $\geq 50 \mathrm{mg} / \mathrm{mL}$, and an NLR $\geq 16$ on admission to the ICU. A meta-analysis that included 979 COPD subjects from 14 studies found that COPD subjects had an average of $35 \%$ intubation for IMV and a mean mortality rate of $45 \% .{ }^{32}$ In the present study, IMV was found to be a risk factor for mortality in ICU patients with ARF and the overall IMV application rate was $47.3 \%$; however, mortality was less than their meta-analysis (37\%). The IMV application rate was higher in the eosinophilic group in our study, although they had a better $\mathrm{pH}$ and $\mathrm{PaCO}_{2}$ and lower APACHE II score on admission. This may be explained by the fact that they had higher rate of arrhythmia and hypoxemia. Steer et al claimed that the "DECAF score" (the Dyspnoea, Eosinopenia, Consolidation, Acidaemia and Atrial Fibrillation score) that uses indices can accurately predict in-hospital mortality in patients hospitalized with acute exacerbations of COPD. ${ }^{33}$ In the present study, we did not use the DECAF score; however, the non-eosinophilic group had a higher rate of mortality. The study also showed that the NIMV failure rate and overall mortality were two times higher in the noneosinophilic group. In contrast, peripheral eosinophilia has been shown to be associated with an increase in all-cause mortality in subjects with airway diseases compared with healthy subjects. ${ }^{34,35}$ However, comparing healthy subjects with eosinophilic COPD subjects in terms of mortality is not an equal comparison. Further studies are needed to evaluate the hospital and long-term mortality in COPD subjects with eosinophilic and non-eosinophilic exacerbations.

\section{Limitations}

There were some limitations to this study. First, it was a retrospective and single-center study with insufficient data; however, we believe that it provides valuable clinical information (due to the large sample size) for assessing ICU outcomes of COPD subjects with eosinophilic and non-eosinophilic exacerbations. Second, COPD severity and spirometry results were not recorded because of the absence of electronically available data; some asthmatic patients may have been misclassified as spirometry with reversibility tests or any tests to distinguish COPD from asthma were not done, in ICU or after discharge. However, patients with asthma, or patients with suspicious COPD, were excluded. Although this may weaken our results, the majority of subjects had 
severe COPD, as determined by the use of long-term oxygen therapy and NIV at home. We can claim that nearly all the COPD patients were in a severe stage of the disease. Our results cannot be generalized for all stages of patients with COPD. Third, due to the retrospective nature of the study, the management of COPD could not be controlled and as such the treatment choices may seem insufficient in some cases. However, the ICU team included all pulmonologists and intensivists, and they followed the same treatment protocol and worked $24 / 7$ in the ICU.

The strength of this study lies in the results showing the eosinophilic COPD exacerbation rate in a large sample size study in a disease-specific respiratory ICU and conducted by a pulmonologist-intensivist. These could increase the reliability of our results.

\section{Conclusion}

COPD exacerbations requiring ICU admission showed peripheral blood eosinophilia in nearly $10 \%$; this was a lower rate of eosinophilia than other COPD exacerbations admitted to the hospital. Non-eosinophilic COPD exacerbations can be more severe, have a higher APACHE II score, and have sepsis-related complications. As such, non-eosinophilic COPD exacerbations have a higher rate of NIMV failure, a longer LOS and a higher mortality rate.

COPD exacerbation management, especially steroid use, is not standardized in the ICU. Besides Anthonisen criteria, a higher NLR and the identification of a peripheral non-eosinophilic state can be helpful for making a decision on antibiotic vs steroid use for the management of COPD exacerbation in the ICU.

\section{Acknowledgment}

The authors thank Dr Sharon Forsyth for editing the manuscript.

\section{Disclosure}

The authors report no conflicts of interest in this work.

\section{References}

1. Khilnani GC, Banga A, Sharma SK. Predictors of mortality of patients with acute respiratory failure secondary to chronic obstructive pulmonary disease admitted to an intensive care unit: a one year study. BMC Pulm Med. 2004;4:12.

2. Alaithan AM, Memon JI, Rehmani RS, Qureshi AA, Salam A. Chronic obstructive pulmonary disease: hospital and intensive care unit outcomes in the Kingdom of Saudi Arabia. Int J Chron Obstruct Pulmon Dis. 2012;7:819-823.

3. Global Initiative for Chronic Obstructive Lung Disease. Global Strategy for Diagnosis, Management, and Prevention of COPD. Global Initiative for Chronix Obstructive Lung Disease; updated 2012. Available from: http://www.goldcopd.org
4. Elliott MW, Confalonieri M, Nava S. Where to perform noninvasive ventilation? Eur Respir J. 2002;19:1159-1166.

5. Ambrosino N, Vagheggini G. Non-invasive ventilation in exacerbations of COPD. Int J Chron Obstruct Pulmon Dis. 2007;2:471-476.

6. Papi A, Bellettato CM, Braccioni F, et al. Infections and airway inflammation in chronic obstructive pulmonary disease severe exacerbations. Am J Respir Crit Care Med. 2006;173(10):1114-1121.

7. Daniels JM, Snijders D, de Graaff CS, Vlaspolder F, Jansen HM, Boersma WG. Antibiotics in addition to systemic corticosteroids for acute exacerbations of chronic obstructive pulmonary disease. Am J Respir Crit Care Med. 2010;181:150-157.

8. Walters JA, Gibson PG, Wood-Baker R, Hannay M, Walters EH. Systemic corticosteroids for acute exacerbations of chronic obstructive pulmonary disease. Cochrane Database Syst Rev. 2009;(1): CD001288.

9. Christ-Crain M, Jaccard-Stolz D, Bingisser R, et al. Effect of procalcitonin-guided treatment on antibiotic use and outcome in lower respiratory tract infections: cluster-randomised, single-blinded intervention trial. Lancet. 2004;363:600-607.

10. Saetta M, Di Stefano A, Maestrelli P, et al. Airway eosinophilia in chronic bronchitis during exacerbations. Am J Respir Crit Care Med. 1994;150:1646-1652.

11. Brightling CE, Monteiro W, Ward R, et al. Sputum eosinophilia and short-term response to prednisolone in chronic obstructive pulmonary disease: a randomised controlled trial. Lancet. 2000;356: $1480-1485$.

12. Kitaguchi Y, Komatsu Y, Fujimoto K, Hanaoka M, Kubo K. Sputum eosinophilia can predict responsiveness to inhaled corticosteroid treatment in patients with overlap syndrome of COPD and asthma. Int $J$ Chron Obstruct Pulmon Dis. 2012;7:283-289.

13. Bafadhel M, McKenna S, Terry S, et al. Acute exacerbations of chronic obstructive pulmonary disease: identification of biologic clusters and their biomarkers. Am J Respir Crit Care Med. 2011;184(6): 662-671.

14. Bafadhel M, McCormick M, Saha S, et al. Profiling of sputum inflammatory mediators in asthma and chronic obstructive pulmonary disease. Respiration. 2012;83(1):36-44.

15. Bafadhel M, McKenna S, Terry S, et al. Blood eosinophils to direct corticosteroid treatment of exacerbations of chronic obstructive pulmonary disease: a randomized placebo-controlled trial. Am J Respir Crit Care Med. 2012;186(1):48-55.

16. Bafadhel M, Davies L, Calverley PM, Aaron SD, Brightling CE, Pavord ID. Blood eosinophil guided prednisolone therapy for exacerbations of COPD: a further analysis. Eur Respir J. 2014;44(3): 789-791.

17. Günay E, Sarınç Ulaşlı S, Akar O, et al. Neutrophil-to-lymphocyte ratio in chronic obstructive pulmonary disease: a retrospective study. Inflammation. 2014;37(2):374-830.

18. Wang RT, Li JY, Cao ZG, Li Y. Mean platelet volume is decreased during an acute exacerbation of chronic obstructive pulmonary disease. Respirology. 2013;18(8):1244-1248.

19. Nava S, Hill N. Non-invasive ventilation in acute respiratory failure. Lancet. 2009;374(9685):250-259.

20. Anthonisen NR, Manfreda J, Warren CP, Hershfield ES, Harding GK, Nelson NA. Antibiotic therapy in exacerbations of chronic obstructive pulmonary disease. Ann Inter Med. 1987;106(6):196-204.

21. Knaus WA, Draper EA, Wagner DP, Zimmerman JE. APACHE II: a severity of disease classification system. Crit Care Med. 1985;13: $818-829$.

22. Ambrosino N, Vagheggini G. Noninvasive positive pressure ventilation in the acute care setting: where are we? Eur Respir J. 2008; 31(4):874-886.

23. Sessler CN, Gosnell MS, Grap MJ, et al. The Richmond AgitationSedation Scale: validity and reliability in adult intensive care unit patients. Am J Respir Crit Care Med. 2002;166(10):1338-1344.

24. Boles JM, Bion J, Connors A, et al. Weaning from mechanical ventilation. Eur Respir J. 2007;29(5):1033-1056. 
25. Snow V, Lascher S, Mottur-Pilson C; Joint Expert Panel on Chronic Obstructive Pulmonary Disease of the American College of Chest Physicians and the American College of Physicians-American Society of Internal Medicine. Evidence base for management of acute exacerbations of chronic obstructive pulmonary disease. Ann Intern Med. 2001;134(7):595-599.

26. Nava S, Karakurt S, Rampulla C, Braschi A, Fanfulla F. Salbutamol delivery during non-invasive mechanical ventilation in patients with chronic obstructive pulmonary disease: a randomized, controlled study. Intensive Care Med. 2001;27(10):1627-1635.

27. Singh D, Kolsum U, Brightling CE, Locantore N, Agusti A, Tal-Singer R; ECLIPSE investigators. Eosinophilic inflammation in COPD: prevalence and clinical characteristics. Eur Respir J. 2014;44(6): 1697-1700.

28. Hospers JJ, Rijcken B, Schouten JP, Postma DS, Weiss ST. Eosinophilia and positive skin tests predict cardiovascular mortality in a general population sample followed for 30 years. Am J Epidemiol. 1999;150:482-491.

29. Dasgupta A, Neighbour H, Nair P. Targeted therapy of bronchitis in obstructive airway diseases. Pharmacol Ther. 2013;140(3): $213-222$.
30. Brightling CE, Bleecker ER, Panettieri RA Jr, et al. Benralizumab for chronic obstructive pulmonary disease and sputum eosinophilia: a randomised, double-blind, placebo-controlled, phase 2a study. Lancet Respir Med. 2014;2(11):891-901.

31. Ongel EA, Karakurt Z, Salturk C, et al. How do COPD comorbidities affect ICU outcomes? Int J Chron Obstruct Pulmon Dis. 2014;9: 1187-1196.

32. Quon BS, Gan WQ, Sin DD. Contemporary management of acute exacerbations of COPD: a systematic review and metaanalysis. Chest. 2008;133(3):756-766.

33. Steer J, Gibson J, Bourke SC. The DECAF Score: predicting hospital mortality in exacerbations of chronic obstructive pulmonary disease. Thorax. 2012;67(11):970-976.

34. Hospers JJ, Schouten JP, Weiss ST, Rijcken B, Postma DS. Asthma attacks with eosinophilia predict mortality from chronic obstructive pulmonary disease in a general population sample. Am J Respir Crit Care Med. 1999;160:1869-1874.

35. Hospers JJ, Rijcken B, Schouten JP, Postma DS, Weiss ST. Eosinophilia and positive skin tests predict cardiovascular mortality in a general population sample followed for 30 years. Am J Epidemiol. 1999;150: $482-491$.

\section{Publish your work in this journal}

The International Journal of COPD is an international, peer-reviewed journal of therapeutics and pharmacology focusing on concise rapid reporting of clinical studies and reviews in COPD. Special focus is given to the pathophysiological processes underlying the disease, intervention programs, patient focused education, and self management protocols.

\section{Dovepress}

This journal is indexed on PubMed Central, MedLine and CAS. The manuscript management system is completely online and includes a very quick and fair peer-review system, which is all easy to use. Visit $\mathrm{http} / / / \mathrm{www}$.dovepress.com/testimonials.php to read real quotes from published authors. 